\title{
Gracia y justicia: el lugar de la utilidad pública (justicia transicional y situaciones de necesidad) \\ Grace and justice: the place of public utility (transitional justice and situations of necessity)
}

\author{
Alfonso Ruiz Miguel \\ Universidad Autónoma de Madrid \\ alfonso.ruiz@uam.es
}

Recibido / received: 11/07/2018

Aceptado / accepted: 13/08/2018

DOI: https://doi.org/10.20318/eunomia.2018.4340

\section{Resumen}

Este texto, que forma parte de un estudio más amplio sobre el indulto, analiza la relación entre el derecho de gracia y la utilidad pública. Tras diferenciar entre razones de clemencia o compasión, de justicia y de utilidad, se examinan separadamente, en primer lugar, los dos criterios básicos que pueden justificar el derecho de gracia: las circunstancias de justicia restaurativa y las situaciones de necesidad; $y$, en segundo lugar, los procedimientos y órganos apropiados para su aprobación (amnistías e indultos, sea generales o particulares).

\section{Palabras clave}

Gracia, clemencia, justicia, utilidad pública, justicia transicional y restaurativa, situaciones de necesidad, amnistía, indultos generales y particulares.

\begin{abstract}
This text, which is part of a wider study about grace, analyses the relationship between legal mercy and public utility. After distinguishing between reasons of clemency or compassion, justice and utility, the essay examines separately, firstly, the two basic criteria that are able to justify legal mercy: circumstances of restorative justice and situations of necessity; and, secondly, the proceedings and authorities suitable for that mercy (amnesties and either general or particular pardons).
\end{abstract}

\section{Keywords}

Grace (Mercy), clemency, justice, public utility, transitional and restorative justice, situations of necessity, amnesties, general and particular pardons.

SUMARIO. 1. Introducción. 2. Utilidad pública y justicia. 3. Justicia transicional y restaurativa: perdón y olvido. 3.1. La emergencia de la Justicia transicional. 3.2. Tensiones entre justicia y paz y modelos de justicia transicional. 3.3. Justicia, olvido y perdón. 4. Situaciones de 
necesidad. 5. Los procedimientos: amnistías, indultos generales e indultos particulares. 6. Conclusión.

\section{Introducción}

Este escrito es parte de un estudio más amplio sobre la justificación filosóficojurídica del derecho de gracia, tanto en sus aspectos sustantivos como, de manera más indirecta, institucionales ${ }^{1}$. Desde un enfoque eminentemente filosófico-jurídico, la pretensión central del estudio es plantear algunos problemas filosóficos generales y sustantivos sobre la justificación ético-política del derecho de gracia, lo que va más allá de la estricta figura del indulto para dar protagonismo a nociones como las de justicia, clemencia, equidad, etc. y a su relación con otras formas de indulgencia ejercidas por distintos actores jurídicos. De manera secundaria el estudio trata de extraer de la reflexión sustantiva algunas posibles derivaciones o sugerencias a propósito de la mejor atribución de competencias a unas u otras instituciones, donde se sitúa el debate sobre el lugar del indulto y la posibilidad y alcance de la amnistía.

El estudio parte de una introducción que propone un análisis histórico de la prerrogativa de gracia, basada en la idea de soberanía, y del contraste entre las ideas de gracia y de justicia, que modernamente se identifican con las exigencias del Estado de Derecho. Desechada la tradicional concepción puramente discrecional de la gracia, se analiza luego si tanto la justicia como la gracia pueden conservar todavía alguna justificación al amparo de tres rúbricas diferentes: la equidad, la clemencia y la utilidad pública. En la equidad la gracia se da la mano con la justicia o, más precisamente, con una forma de justicia indulgente que modera la justicia rigurosa. En la clemencia, entendida restrictivamente como compasión o misericordia, la gracia se presenta en contraste con la justicia y la igualdad, lo que resulta de difícil justificación salvo mediante una regulación legal específica de algunos supuestos, como la enfermedad incurable o la pena natural. Y, en fin, por la utilidad pública, que apela al interés general, la gracia puede justificarse como una excepción a la justicia en situaciones críticas, sea de naturaleza fundacional (justicia transicional y restaurativa), o sea por otros motivos de especial y grave necesidad. El presente escrito reproduce únicamente el último apartado del estudio, proponiendo en la conclusión una rápida síntesis de las tres rúbricas mencionadas.

\section{Utilidad pública, clemencia y justicia}

En la justificación del derecho de gracia por razones de utilidad pública el término "utilidad" se usa en un sentido amplio, no estrictamente asociado con el utilitarismo, para comprender razones diferentes a las de clemencia o compasión y a

\footnotetext{
${ }^{1}$ A su vez, el estudio forma parte de un proyecto de investigación sobre el indulto (DER2013-45562-P de la Secretaría de Estado de Investigación del Gobierno de España), dirigido por el profesor Fernando Molina, que se publicará en dos versiones: una más sintética, en inglés, y otra completa, en castellano. Con algunas adiciones, especialmente en el epígrafe 3, el presente texto corresponde al último de los cuatro apartados de mi estudio más amplio ("Gracia y justicia: más allá del indulto”, en Molina y Carracedo, 2018). Los tres restantes apartados se han publicado previamente en distintas revistas: vid., por el orden de los apartados, Ruiz Miguel 2018b, 2017 y 2018a (advierto también de que la Introducción y la Conclusión del presente estudio son prácticamente comunes con las del primero de esos tres escritos).

Mi especial agradecimiento a Eva Carracedo, Enrique Peñaranda y Francisco J. Laporta. Asimismo, me he beneficiado del excelente texto preparado para este mismo proyecto de investigación por Liborio L. Hierro, "Sobre el indulto. Razones y sinrazones", que cito con referencia a sus apartados. Agradezco también las sugerencias de las dos evaluaciones anónimas de esta revista, que he atendido prácticamente en todos sus puntos, excepto en las sugerencias de ampliación a la jurisprudencia constitucional y administrativa, que excederían el marco de este estudio.
} 
las de justicia, abarcando criterios de necesidad o urgencia social, especial provecho o beneficio público y similares.

Con tal significado amplio, la utilidad pública se puede distinguir claramente de la idea de clemencia por dos criterios fundamentales: el primero, que mientras la clemencia se ejerce esencialmente en favor de personas determinadas y por razones estrictas de compasión, la utilidad pública constituye un principio genérico, de carácter teleológico, cuyo destinatario es colectivo, idealmente, la comunidad en su conjunto, una diferencia por la que en estos casos parece más propio hablar de lenidad que de indulgencia ${ }^{2}$; el segundo, que mientras la clemencia parece esencialmente discrecional, la utilidad pública se presenta siempre como una finalidad que la autoridad está obligada a perseguir y a realizar en la medida de lo posible.

Las relaciones entre la utilidad pública y la justicia son más complejas que con la clemencia, como puede observarse con tres rápidas observaciones. En una primera aproximación, desde una concepción liberal al menos, hay una conexión normativa ordinaria entre ambas en cuanto que la garantía de los criterios de justicia se integra como un componente de la noción de utilidad pública en sentido amplio, equivalente a interés general o bien común: idealmente, si la garantía de los derechos básicos en que consiste la noción de justicia es el núcleo de la justificación del Estado, parece que no puede admitirse un conflicto frontal y generalizado entre justicia y utilidad pública. Bajo una segunda reflexión, la noción de utilidad pública se utiliza en ocasiones en un significado más restringido para calificar a las acciones y políticas necesarias para el funcionamiento del Estado y la prosperidad de la sociedad (infraestructuras, fomento, bienestar social...); aunque tales acciones y políticas puedan ser condiciones necesarias para la realización de los derechos más básicos, la utilidad pública en ese sentido suele diferenciarse de la justicia. Como última observación, en fin, la utilidad pública puede llegar a presentarse en conflicto con la noción de justicia: Kant (1795: 146-147) así lo aceptó cuando defendió la resolución del conflicto mediante el fiat iustitia et pereat mundus, justo la respuesta antagónica a la que había dado Hume pocos años antes:

"Cuando la ejecución de la justicia se obtendría con consecuencias muy perniciosas, en tales emergencias tan extraordinarias y apremiantes, tal virtud debe ser suspendida para dar paso a la utilidad pública. La máxima fiat Justitia \& ruat Cœlum, hágase la justicia aunque se destruya el universo, es palmariamente falsa... [...] Salus populi suprema Lex, la salvación del pueblo es la ley suprema..." (1777, II. xiii: 489).

Al igual que ocurre con la clemencia, el derecho de gracia es precisamente uno de los campos abonados de esa posible discordancia entre la justicia y la utilidad pública.

\footnotetext{
2 En el estudio más amplio utilizo el término "clemencia" para referirme al sentido estricto de reducción o perdón de la pena por razones de compasión o misericordia, usando en general el de "indulgencia" para referirme a toda mitigación o exclusión de la sanción en beneficio del acusado o condenado, y mucho más raramente el más genérico y neutro de "lenidad". Por lo demás, las nociones de indulgencia y de lenidad vienen a coincidir con el significado amplio de la clemencia (y la gracia), como moderación en la sanción, con dos salvedades: primera, que en una cultura impregnada de influencias cristianas como la nuestra las ideas de clemencia y, aunque en menor medida, de indulgencia llevan una connotación valorativa favorable de la que carece la idea de lenidad, cuyo uso, más descriptivo, es compatible con la crítica por su exceso o abuso; y, segunda, que el carácter virtuoso de la clemencia parece más marcado que el de la indulgencia, pues mientras no resulta chocante hablar de exceso de indulgencia, si lo parece hablar de exceso de clemencia (lo que quizá no sea solo una peculiaridad del castellano, sino que podría estar arraigado desde la cultura clásica: así, conforme a la interpretación de Anthony Duff, la clemencia (દ́रéńбaı) aristotélica es necesariamente virtuosa: "ser clemente [merciful] es ser indulgente en el momento justo, sobre las cosas apropiadas, hacia la gente adecuada, por el fin justo y de la forma justa [Ética nicomáquea, 1106b]" (Duff, 2011: 469).
} 
Dejando aparte los casos en los que la utilidad pública se utiliza como mera fachada para encubrir indultos o amnistías por inconfesables intereses parciales, pueden distinguirse dos tipos de supuestos en los que aquel criterio podría justificar el uso del derecho de gracia, ambos caracterizados por producirse en circunstancias críticas: de un lado, los supuestos habitualmente denominados de "justicia transicional", cuyo paradigma son las transiciones democráticas, y, de otro lado, los basados en otras razones de necesidad o acusada conveniencia, que agrupan situaciones de distinta naturaleza, como el hacinamiento de las prisiones, el intercambio de espías o prisioneros entre Estados, la liberación de presos ante un secuestro con rehenes y otros similares. La diferencia más relevante entre los dos tipos de casos no está tanto en su naturaleza política o económica como en que solo en el primero parece apropiado hablar de perdón estatal en el sentido estricto de remisión de una pena en aras de una cierta reconciliación. Analizaré primero los principales problemas de justificación sustantiva de uno y otro tipo de supuestos, reservando para el último apartado el análisis de los procedimientos.

\section{Justicia transicional y restaurativa: perdón y olvido}

La apelación a la utilidad pública por razones políticas fundacionales está en el origen de la institución y del término "amnistía" (ápvnotía: olvido), con los que Atenas reintrodujo la democracia en el 403 a.C. tras el gobierno de los Treinta Tiranos $^{3}$. Es también, seguramente, el argumento en favor del derecho de gracia más pujante y el más resistente a su abolición. Entre los varios y complejos problemas que subyacen a la justicia transicional, que ha recibido una enorme atención académica en los últimos años, tras unas consideraciones sobre el alcance y relevancia de la teorización de esa especial forma de justicia (§ 3.1 ), me centraré después en las condiciones esenciales de su legitimidad en el marco de las tensiones entre justicia y paz (§ 3.2), para concluir el apartado con unas reflexiones sobre las relaciones entre justicia, olvido y perdón.

\subsection{La emergencia de la Justicia transicional}

Se denomina situaciones de justicia transicional -0 , con un matiz diferente, restaurativa ${ }^{4}$ - a un conjunto de prácticas y decisiones políticas, entre las que suelen figurar las amnistías, en las que se producen restricciones a una aplicación estricta de la justicia en beneficio de un futuro pacífico y respetuoso del imperio de la ley y de la democracia. Originariamente, y ese es todavía hoy su núcleo significativo, la noción de justicia transicional, se comenzó aplicando a las transiciones a la democracia de Latinoamérica en los años 80 y de Sudáfrica y los países del Este en los 90, que, con los juicios de Núremberg y Tokio en el trasfondo, pretendían afrontar las transiciones a sistemas democráticos desde un régimen dictatorial responsable de graves

\footnotetext{
${ }^{3}$ Vid. sobre ello Elster (2004: 3) que comienza afirmando que la "justicia transicional democrática es casi tan vieja como la democracia misma".

4 La justicia restaurativa se suele proponer como una manifestación o concreción de la justicia transicional pero de dos formas diferentes. En su forma descriptiva, se ha distinguido conceptualmente entre tres tipos de instrumentos o mecanismos jurídicos de la justicia transicional, que pueden darse conjuntamente en la práctica: los de justicia retributiva (como los juicios penales, con su contrapartida en las amnistías), los de justicia restaurativa (comisiones de verdad, reparaciones materiales y simbólicas, etc.) y los de justicia institucional (reformas judiciales y administrativas, depuraciones, etc.) (cf. Forcada, 2011: 23-27). En forma valorativa, por su parte, la justicia restaurativa se presenta como un modelo ideal de justicia transicional en contraposición a los arreglos meramente transaccionales insuficientemente justos (salvo advertencia en contrario, aquí utilizo la expresión preferentemente en este segundo sentido).
} 
atrocidades y abusos ${ }^{5}$. Sin embargo, el concepto ha sufrido una considerable expansión en los últimos años hasta aplicarse también a conflictos tanto interestatales como intraestatales, e incluso dentro de sistemas democráticos ${ }^{6}$, como es muestra eminente de este último caso el largo proceso de negociaciones entre la guerrilla y el Estado colombiano. Aunque este significado ampliado es conceptualmente marginal respecto del significado originario y central, hasta el punto de que tiende a diluir el carácter políticamente fundacional de la justicia transicional, ambos tienen en común la aplicación de mecanismos de transacción entre posiciones en conflicto donde tiende a dominar la búsqueda de la pacificación sobre la pretensión de hacer justicia estricta ${ }^{7}$. De ahí la utilización en tales contextos de expedientes como la amnistía, sugerentemente definida por una estudiosa brasileña como "a medida de interesse coletivo, inspirada na necessidade de paz social a fim de se fazer esquecer comoçoes insteinais e pacificar espíritos tumultuados" (Seixas, 2014).

La inclusión de las amnistías políticas en el marco de la justicia transicional parece sugerir la aparición de un llamativo giro en la relación entre el Derecho internacional y los Derechos nacionales ${ }^{8}$. Al parecer, la doctrina dominante en esta nueva materia teórico-práctica, hoy ya consolidada con el nombre de Justicia transiciona $l^{9}$, tiende a asumir una serie de criterios tanto conceptuales como prácticos que, junto a efectos encomiables, en determinados casos pueden producir también consecuencias indeseables. La idea fundamental de esta nueva disciplina postula la existencia de ciertos principios jurídicos unificadores y específicos de las situaciones de transición, en último término afincados en el Derecho internacional de los derechos humanos, que operarían no solo como limitaciones de la acción política (sea prohibiendo, en el caso de ciertas modalidades de amnistía, sea obligando o recomendando, en el caso de las comisiones de la verdad) ${ }^{10}$, sino también como

${ }^{5}$ Cf. Rangelov y Teitel (2014: 338-339); y Turner (2013: 195-196 y 204). En realidad, los precedentes de la justicia transicional como expresión de momentos políticos fundacionales se han llegado a remontar desde la Grecia clásica hasta las ejecuciones de Carlos I y Luis XVI (Teitel, 2000: 29).

${ }^{6}$ Cf. Szablewska y Bachmann (2015: 340-343); Rangelov y Teitel (2014: 345-349); Turégano, (2013b: 47-49); y Turner (2013: 196-197 y 202). Esta última autora ha llegado a afirmar que ya desde finales del siglo XX la etiqueta de "transición" se aplica de manera muy diferente, pues "más que referirse a conflictos interestatales o dictaduras militares, la mayor parte de la actividad de la justicia transicional ha surgido como resultado de acuerdos de paz. El final de un conflicto por un acuerdo negociado significa que no había claros vencedores o perdedores".

${ }^{7}$ Que el significado amplio de la justicia transicional sea conceptualmente marginal no quiere decir que también lo sea materialmente, es decir, respecto del número de casos a los que se ha aplicado: así, entre 1970 y 2004 se han computado 129 países que han utilizado mecanismos de justicia transicional (con 424 amnistías, 267 enjuiciamientos, 68 comisiones de la verdad, etc.), de los cuales solo 74 (con 49 enjuiciamientos y 46 amnistías) corresponden a países que han pasado de una dictadura a la democracia (cf. Forcada, 2011: 79-80).

8 Una buena y muy útil descripción de la evolución contemporánea del Derecho internacional de los derechos humanos y del Derecho penal internacional, con conclusiones muy mesuradas, en Almqvist (2013).

${ }^{9}$ En efecto, en cuanto materia de estudio, la Justicia transicional ha dado lugar a un campo con la suficiente pujanza y autonomía como para contar desde 2007 con una revista académica cuatrimestral, publicada por Oxford Academic: el International Journal of Transitional Justice. El logro es llamativo si se tiene en cuenta que la expresión "justicia transicional" fue acuñada en 1991 por Ruti Teitel (Rangelow y Teitel, 2014: 338) y que en 1999 un científico social muy cercano al tema como Jon Elster todavía no la daba por establecida (Elster 2004: xii; para más datos sobre el tema, indicando sin embargo 1995 como fecha de fijación de la etiqueta, cf. Forcada, 2011: 10 y 97-98). Quizá la fortuna del término pudo llegar tras el seminal libro de Teitel sobre el tema (Teitel, 2000), que en lo esencial es una defensa del papel político del Derecho y de la consiguiente necesidad de compromisos entre el realismo político y el idealismo moral. Para una incisiva crítica de la "macrodisciplina", remito al valioso estudio de Forcada (2011: 112, y especialmente: 94 ss.), que en general parte de una visión escéptica sobre la Justicia transicional, el Derecho penal internacional y hasta el mismo Derecho internacional, que solo en las páginas finales mitiga con una contrastante y para mí algo candorosa apelación a la educación.

10 En relación con las limitaciones de las amnistías, véase Ollé (2013); cf. también Rangelov y Teitel, (2014: 340-342) que destacan que en la presente internacionalización jurídica "cada vez más aparece que la justicia transicional implica un emergente «derecho a la rendición de cuentas [accountability]», 
definitorios y configuradores de las situaciones de transición y de las medidas que se deben adoptar en ellas ${ }^{11}$.

Si a tales principios se une, de un lado, el carácter performativo - es decir, de creación de realidad por parte de la sola teoría- del que la nueva disciplina presume por su gran influencia práctica gracias a la intensa interacción entre académicos, agencias internacionales y activistas ${ }^{12}, y$, de otro lado, la tendencia a adquirir vida propia de los conceptos jurídicos en este campo ${ }^{13}$, son fácilmente inteligibles las objeciones que en nombre de las posibilidades de la paz y la estabilidad democrática en distintos contextos políticos se hacen a la doctrina de la justicia transicional. Y si además esa performatividad y esa creatividad conceptualista se pretenden aplicar a situaciones transicionales de carácter marginal, en especial dentro de sistemas democráticos que han sufrido conflictos sociales o territoriales, a las tensiones entre la justicia y la paz es fácil que se sumen, disfrazadas bajo el manto del Derecho, tensiones políticas derivadas de las pretensiones de deslegitimación y debilitamiento de democracias razonablemente constituidas y asentadas ${ }^{14}$.

incluyendo el derecho a la verdad, a las reparaciones, así como a la persecución penal" (p. 341). No obstante, esta tendencia es más clara en la Corte Penal Internacional y en la Corte Interamericana de Derechos Humanos que en el Tribunal Europeo de Derechos Humanos (cf. Klinkner y Smith, 2015, donde para una profundización del tema es muy útil el elenco bibliográfico de documentos y decisiones judiciales internacionales relevantes en pp. 25-28; Kogan, 2015; y Gil y Gil y Maculan, 2013: 151-154). Aun así, la cuestión misma no deja de ser disputada entre los cultivadores del Derecho internacional, pues también se han expresado dudas sobre la existencia y alcance de tales limitaciones (así, cf. Forcada, 2011: 30 y ss., $47-49$ y 162-163).

${ }^{11}$ Cf. Turner (2013: 198 y ss.) que destaca cómo "ha emergido como dominante una narrativa ecuménica [overarching], manifestada en una convergencia de opinión de que existen ciertos principios unificadores de la justicia en transición y de que esos principios normativos están incorporados en mecanismos como juicios, comisiones de la verdad y reparaciones" (p. 198); y, mucho más críticamente, Forcada, 2011, $\S 2.1$, que se refiere gráficamente a la "«plantilla jurídica» transicional", especialmente en referencia a la para él discutible prohibición jurídico-internacional de las amnistías que no garantizan el derecho de las víctimas a recursos efectivos para la reparación del daño, su derecho a la verdad y a castigar a los responsables de genocidios, delitos de lesa humanidad, guerra, torturas y desapariciones forzadas y otras violaciones graves de los derechos humanos (pp. 30-32). En fin, para una propuesta "parcialmente integrativa del Derecho nacional y el Derecho internacional" en situaciones de transición, véase Turégano (2013b: 50 y ss.).

${ }^{12}$ Cf. Rangelov y Teitel (2014: 340); Turner (2013: 197-198); y Forcada (2011: 10-11 y 24).

13 “... la emergencia del concepto de transición, y consecuentemente de justicia transicional, representa un momento de fuerza performativa. [...] En términos prácticos esto significa que los mecanismos transicionales son evaluados dentro de los nuevos parámetros de la justicia transicional, pero en términos conceptuales significa que la necesidad de estos mecanismos y reformas debe también ser interpretada a la luz del concepto. [...] Una vez se ha establecido un concepto, una vez el campo se ha constituido, el concepto adquiere forma jurídica por sí mismo" (Turner, 2013: 200). La descripción recuerda, sin duda, la famosa crítica de Jhering a la capacidad de aparearse y procrear del homunculus de la Jurisprudencia conceptual con la que comienza una de sus obras (Jhering, 1885: 41-42).

${ }_{14}$ Como resultará evidente, estoy pensando en un conflicto como el que se sufre en Cataluña, en el que han tenido gran protagonismo e importancia los intentos del campo secesionista por atraer a su causa el apoyo internacional, tanto oficial como informal. No me extrañaría nada que en la próxima hoja de ruta del secesionismo que no cesa se incluyera la pretensión de aplicar la doctrina de la justicia transicional. A mi modo de ver, tal pretensión debería ser tajantemente rechazada por el Estado, como, salvadas las distancias, se logró hacer en el caso de la banda terrorista ETA. Ese rechazo no debería excluir, según las circunstancias, la posibilidad de una amnistía a los eventuales condenados por los delitos que correspondan en el denominado "procés", siempre que fuera en forma limitada y condicional: limitada, porque en principio debería reducirse a las eventuales penas de prisión antes que a las de inhabilitación y multa; y, en todo caso, condicional, porque debería ser revocable si las personas amnistiadas incumplieran el compromiso de lealtad básica con los mecanismos legales y constitucionales establecidas para los cambios políticos. Y, a propósito de lealtad, los próximos tiempos deberían ser buena hora para impulsar una reforma, en principio solo legal, que proponga un modelo de democracia un poco más militante, en la que, por ejemplo, los juramentos - en la actualidad objeto de broma política, en buena parte por una jurisprudencia constitucional que estimo radicalmente equivocada - se puedan comenzar a tomar en serio, especialmente en su exigibilidad estricta como condición para el acceso a cargos públicos. 


\subsection{Tensiones entre justicia y paz y modelos de justicia transicional}

Por ir entrando en el punto más doliente de la noción de justicia transicional, hablar de "justicia" para referirse a la búsqueda de soluciones que sacrifican en una u otra medida a la justicia en aras de la paz y otros valores tiene el grave inconveniente de velar o suavizar los inevitables e indudables desafíos que la paz suele presentar a la justicia, que pueden ser tan graves como las que la justicia a veces presenta a la paz $^{15}$. En esta última dirección, se ha puesto de manifiesto cómo funcionarios y activistas internacionales favorables a la justicia penal internacional tienden a considerar a esta como terapéutica y eficaz frente a la evidencia de que en ocasiones dificulta la consecución de la paz ${ }^{16}$. Por las mismas razones, en la dirección inversa aquí considerada, los procesos de pacificación y las amnistías asociadas a ellos pueden comportar onerosas renuncias a la acción de la justicia penal (Teitel, 2000: 51 ss.). La colonia de Nueva Inglaterra - que, tras ofrecer una fiesta de reconciliación a los condenados a la horca arrepentidos, los ahorcaba al día siguiente (Hampton, 1988a: 158) - seguía sin duda una práctica bárbara pero no incoherente con una concepción retribucionista de la pena, para la que el perdón no exime de la penitencia.

Hasta qué punto expresiones como "justicia transicional" o "justicia restaurativa" difuminan el contraste entre los procesos de pacificación y la justicia (punitiva) depende de la naturaleza específica de tales procesos ${ }^{17}$. En la justicia transicional se pueden distinguir dos modelos que ocupan los extremos de una escala gradual: en uno de los polos se sitúa el modelo transaccional, que tiene la pretensión de ser un simple borrón y cuenta nueva tras el que la paz se pretende obtener a cambio de una justicia penal limitada, adoptada en malas circunstancias y como lo mejor que bajo tales circunstancias se puede conseguir (second best); en el polo opuesto, se sitúa el modelo idealmente restaurativo, de integración del pasado en un nuevo tiempo de justa concordia, que, a través de "comisiones de la verdad" u otros procedimientos similares, se abre otorgando alguna voz y reconocimiento a las víctimas, así como aplicando políticas de perdón que limitan o renuncian a los castigos de los responsables de graves delitos en el periodo anterior ${ }^{18}$.

\footnotetext{
15 Sobre el tema, en favor de la prioridad de la justicia en forma de memoria y "castigo garantista", vid. Vázquez (2009); en una línea más matizada vid. Escudero (2017), quien, aun dentro de "límites que nunca deben traspasarse" (sobre todo mediante amnistías incondicionadas ante crímenes contra la humanidad), concede un amplio papel al "contexto político" y a las "particulares circunstancias de cada caso" (pp. 109, 104 y 105, respectivamente). Precisamente, la fuerte dependencia contextual de este tipo de situaciones ha justificado la negativa a generalizar una teoría de la justicia transicional (cf. Elster, 2004: xi y 77). En cierto contraste con los anteriores, es muy recomendable también un provocativo y documentado ensayo de David Rieff cuya tesis fundamental -argumentada con cierta confusión sistemática plagada de brillantes destellos críticos- es que se debe promover el olvido, y preferiblemente el perdón, cuando hacer justicia es más dañino que buscar la paz (Rieff, 2016: 109-114). Nada que objetar a esta propuesta, cuyo diablo evidente se encuentra en los detalles de su aplicación práctica, salvo por algunos excesos argumentativos de Rieff, como sus afirmaciones sobre la obviedad irrelevante de que la historia y la humanidad misma terminarán siendo olvidadas (al igual, por cierto, que la tierra y el sistema solar desaparecerán, sin que nada de ello deba importarnos gran cosa en nuestros afanes y juicios), su distanciamiento del universalismo ético (y por tanto de un básico objetivismo ético en nombre de la inconmensurabilidad e irreconciliabilidad de las distintas visiones del mundo) y, en general, su exceso de insistencia en los riesgos de abuso y manipulación de la memoria colectiva (que en realidad, Rieff siempre termina por matizar con sanas concesiones a la necesidad de una cierta justicia).

${ }^{16} \mathrm{Cf}$., en referencia a los tribunales internacionales impuestos en Camboya o Sierra Leona, recomiendo el texto de Nowen (2012: 342-347). Asimismo, para una consideración crítica general sobre la justicia penal internacional, desconfiando de pretendidas soluciones universales e intemporales, también recomiendo el excelente estudio de Forcada (2011: 17-21).

17 Sobre las tensiones en los procesos de transición entre justicia retributiva y justicia restaurativa (en el sentido descriptivo indicado supra, nota 4) es muy recomendable el análisis de Betegón (2013).

${ }^{18}$ Cf. Williams (2012: 279-284), en quien me inspiro con libertad. No obstante, para una visión más amplia y compleja de la que yo propongo en el texto, véase De Páramo (2013: 12), que entre otras cosas advierte oportunamente de que en el contraste entre negociación y argumentación deliberativa no se deben
} 
En los dos modelos se establecen excepciones importantes en los procedimientos y exigencias sustantivas de justicia en nombre de la pacificación, sin que tales excepciones quedan en realidad anuladas o superadas por otra forma de justicia alternativa. Esto no significa que esas excepciones no puedan ser convalidadas o justificadas, si bien mucho más claramente en el modelo restaurativo, por dar lugar a una situación política pacífica y democrática que, mirando adelante, pueda operar como condición de la justicia. Pero ha de reconocerse que se trata de una justicia proyectada hacia el futuro y asentada sobre una cancelación defectiva de la injusticia pasada ${ }^{19}$. En todo caso, aceptada la justificabilidad de algunas de esas formas de cancelación, sus criterios de justificación no se pueden condensar en una simple receta. Dependen de muy diversas circunstancias, no siempre fáciles de sopesar por sí mismas y en las relaciones entre ellas, como la relevancia concedida a comisiones de la verdad o similares, el tiempo transcurrido desde los crímenes exculpados, el alcance de las amnistías acordadas, la no convalidación de delitos gravísimos como los imprescriptibles o, en fin, la actitud oficial de reconocimiento sólido y duradero de que el perdón no entraña el olvido.

\subsection{Justicia, olvido y perdón}

En su conocido libro sobre la que denominó "tercera ola" democratizadora, Samuel Huntington sintetizó el estado de la cuestión a propósito de las distintas transiciones democratizadoras entre los años 1974 y 1991 mediante esta llamativa guideline: "Reconoce que ante la cuestión de «perseguir y castigar vs. perdonar y olvidar» cada alternativa presenta graves problemas y que el curso de acción menos insatisfactorio bien puede ser: no persigas, no castigues, no perdones y, sobre todo, no olvides" (Huntington, 1991: 231). No es cuestión de entrar aquí en la mayor o menor pertinencia de este juicio desde el punto de vista de la ciencia política, que en principio es el adoptado por Huntington, ni en discutir si su recomendación es una mera regla técnica o comporta compromisos normativos más profundos. La perspectiva aquí adoptada es filosófica y directamente normativa, como la adoptada por Carlos Santiago Nino en su libro Radical Evil on Trial, un detallado y profundo análisis sobre el tema que va mucho más allá del caso argentino que inicialmente motivó su escritura y merece ser leído ${ }^{20}$.

Dentro de la anterior perspectiva normativa, me voy a detener sobre todo en la compleja relación entre olvido y perdón, que ha de partir de la difícil y discutida noción de perdón. A propósito del derecho de gracia, desde el punto de vista filosóficojurídico aquí asumido es claro que, conceptualmente, el perdón puede ser tanto incondicionado como condicionado, se extienda esta última noción a la posibilidad y justificabilidad de amnistías limitadas a ciertos delitos y de conmutaciones o indultos parciales o se restrinja a la posibilidad y justificabilidad de someter a condiciones específicas la obtención de la gracia, incluida su revocabilidad ${ }^{21}$. Tampoco tiene

comparar heterogéneamente modelos ideales y prácticas fácticas y de que en la realidad no se dan los modelos puros sino combinaciones de uno y otro, existiendo "argumentaciones estratégicas y negociaciones deliberativas".

${ }^{19}$ Cf. Zagrebelsky (1974: 102). Sobre la "justicia histórica", especialmente a través de comisiones de la verdad, y las tensiones entre verdad y justicia, vid. Teitel (2000: cap. 3).

${ }^{20}$ En concreto, para una crítica de la preferencia de Huntington por los arreglos políticos en detrimento de las acciones penales, cf. Nino (1996: 200 ss.). Por lo demás, Nino dedica amplio espacio al tema de la justificación de la pena, que deliberadamente no se aborda en la investigación de la que este escrito forma parte.

${ }^{21}$ En este sentido, y en principio con buen criterio, la vigente ley española de indulto, todavía de 18 de junio de 1870, deja sin efecto la conmutación desde que el indultado incumple voluntariamente la pena pendiente de cumplimiento (art. 14) y prevé la posibilidad de imponer "las demás condiciones que la justicia, la equidad o la utilidad pública aconsejen" (art. 16). No obstante, la revocabilidad de los indultos es un tema legalmente oscuro en los indultos totales, porque el artículo 18 utiliza una fórmula ambigua, 
mayor sentido profundizar en el debate filosófico de si, conceptualmente, el perdón está reservado en exclusiva a la víctima, pues es claro que en el significado jurídico y no directamente moral que tienen indultos y amnistías el Estado puede ejercer el derecho a perdonar como contrapunto del derecho a castigar, al menos si así lo reconoce el sistema jurídico de que se trate ${ }^{22}$. Es cierto que esa posibilidad no implica necesariamente la justificación última o moral de aquel derecho a perdonar, que depende precisamente de que el castigo jurídico se conciba también como un derecho (o, mejor, como un deber excepcionable) justificado del Estado y no como un deber inexcusable. Precisamente, dilucidar si hay razones que pueden justificar la excepcionalidad de tal deber es lo que aquí se pretende analizar.

A mi modo de ver, una de las condiciones relevantes para la aceptabilidad moral de las amnistías en situaciones de transición y similares es que la noción de perdón no se identifique con la de olvido. La etimología del término amnistía, olvido, no debe confundirnos. Conceptualmente, mientras el perdón es una acción, como tal voluntaria, por la que se cancela o se da por revertida la acción dañosa de otra persona, el olvido es un mero hecho, algo que, individualmente considerado, ocurre con independencia de nuestra voluntad ${ }^{23}$. Cuando Hannah Arendt caracterizó al perdón como el remedio inventado contra la irreversibilidad de las acciones humanas pasadas, en parangón a la promesa como remedio social a la dificultad humana para predecir el futuro, no estaba pretendiendo el imposible de que el perdón revierta o cancele literalmente el pasado, como tampoco la promesa es capaz de, literalmente, predecir el futuro ${ }^{24}$ : en ambos casos estamos, a diferencia del olvido, ante artefactos sociales o convenciones que nos permiten obrar con un cierto control sobre el pasado y el futuro. Es un control que sabemos y debemos reconocer como limitado, sin creer que podamos convertir lo mal hecho en no hecho (Hampton, 1988b: 41), o que nuestras promesas se verificarán como un fenómeno natural. El perdón, así, no se confunde conceptualmente con el olvido. En el plano de los hechos puede ser que perdonar de forma incondicional, "de corazón", entrañe olvidar completamente, pero en el plano normativo el perdón, especialmente el perdón jurídico y público del que aquí tratamos, no debe ir acompañado del olvido si se quiere que el mal ya cancelado no vuelva a repetirse ${ }^{25}$. Aquí conviene precisar que aunque el olvido no sea una

si no también contradictoria, al decir que "La concesión del indulto es por su naturaleza irrevocable con arreglo a las cláusulas con que hubiera sido otorgado", de manera que parece no excluirse que un indulto total pueda concederse con cláusulas condicionales que permitan su revocación; en la práctica, parece ser usual que los decretos de indulto impongan la condición resolutoria de "no volver a cometer delito doloso durante el tiempo normal de cumplimiento de la condena" (cf. Sánchez-Vera, 2008: 21 y nota 44). 22 El criterio de que el perdón es, a diferencia de la gracia o la clemencia, algo esencialmente personal que está reservado a la víctima como un cambio en sus sentimientos que precede a la reconciliación, es muy común en la filosofía moral (cf., por ejemplo, Murphy, 1988: 21, 26-27 y 33-34; Hampton, 1988a: 157-158; Derrida, 1999; y Arendt, 1974: 261-262). Sin embargo, no hace falta negar la pertinencia de ese significado del perdón, eminentemente moral, para aceptar la posibilidad de un significado diferente, de carácter jurídico, por el que ciertos actos $-\mathrm{y}$ no solo el indulto, sino también el cumplimiento de la pena- se entienden como cancelación o condonación por parte del Estado de la deuda contraída por el delito.

${ }^{23}$ Cf. Murphy (1988: 15), que recoge la distinción del obispo inglés del siglo XVIII Joseph Butler.

24 Arendt (1972: 256-257). En cambio, dado el concepto de perdón que vengo defendiendo, no puedo seguir a Arendt cuando, tras relacionarlo con el amor al agresor, añade que, como "asunto eminentemente personal (aunque no es necesario que sea individual o privado)", el perdón "no sólo es apolítico sino antipolítico, quizá la más poderosa de todas las fuerzas antipolíticas humanas", concluyendo que "quizá debido a su contexto religioso, quizás a su conexión con el amor que acompaña a su descubrimiento, siempre se ha considerado no realista e inadmisible en la esfera pública" (ib.: 261262).

25 La idea de que "[p]erdonar de corazón supone de hecho olvidar. Y olvidar completamente" es de Amelia Valcárcel, que explica: "Aquel que no olvidare, ¿podría no dejar traslucir en su acción el recuerdo del daño recibido? Tendría que ser más que hombre para lograrlo". Pero, junto a ello, desconfiando de todo perdón como injusto (salvo los "perdones fundantes" o restaurativos), también precisa enseguida que "casi todo perdón está condicionado: se perdona algo a condición de que no vuelva a repetirse..." (Valcárcel, 2010: 58 y 130-131). El hilo conductor del libro de Valcárcel, que comparto, está dirigido a 
acción sino un hecho, y como tal algo no intencional en la esfera individual, eso no significa que su aceptación pasiva o incluso su fomento sean moralmente irrelevantes en la esfera pública. Por eso perdonar pero no olvidar puede ser una condición de legitimidad de los perdones propios de la justicia restaurativa. Y así como el olvido, tanto el público como el privado, es esencialmente pasivo, el no olvido requiere actividad, y una actividad dedicada y duradera que en el caso de la memoria pública debe impulsarse también oficialmente ${ }^{26}$.

Con perdón o sin él, no olvidar se muestra como el mejor antídoto frente al olvido buscado por quien no quiere el perdón porque no cree haber hecho nada malo, incluso aunque el mal sea radical y, por tanto, imperdonable ${ }^{27}$. No creo que exista mejor muestra de esta impostura que un breve artículo de Carl Schmitt, originalmente publicado como anónimo en 1949, titulado "Amnistía o la fuerza del olvidar" ${ }^{28}$. La médula del texto es la apelación a finalizar la "guerra civil fría" no mediante la aniquilación del vencido - que sería, dice, la respuesta simple del comunista-, sino del "único modo humano" de hacerlo, mediante "la fuerza de olvidar", y en "un acto recíproco":

"No es ni una gracia ni una limosna. Quien recibe la amnistía, debe también darla, y quien la da debe saber que él también la recibe".

La calaña ética de la propuesta - que no elude apoyarse de forma facilona en la etimología griega de "amnistía" - podría pasar desapercibida si no se añade que, según Schmitt,

"La desnazificación fue guerra civil fría. La característica de esta guerra civil consiste en tratar al otro como criminal, asesino, saboteador y gánster. En un sentido horrible, la guerra civil es una guerra por el Derecho, puesto que cada una de las partes se sienta sobre su Derecho como sobre un botín"

Lo más llamativo de este escrito no es tanto que el valedor de la importancia de la excepcionalidad y de la concepción de la política en términos de amigo-enemigo apelara a la vuelta a la normalidad y a una suerte de reconciliación a través del olvido (eso sí, una idea que, genio y figura, Schmitt no puede dejar de considerar en términos de fuerza, revestida además como "un residuo de derecho sagrado"). Lo más llamativo y a la vez provocativo es que en su incitación al olvido está del todo ausente la noción de perdón (Begnadigung), una palabra que aparece una sola vez a lo largo

vindicar como deber esencial, hoy, el no olvidar, quizá como única esperanza contra la repetición del mal.

${ }^{26}$ A modo de ejemplo: la reconstrucción de Dachau o Auschwitz como museos conmemorativos es una actividad contra el olvido; la inactividad ante el Valle de los Caídos (construido originariamente para el reposo de "los héroes y mártires de la Cruzada" y donde se hallan enterrados en lugares muy prominentes el dictador Francisco Franco y el jefe del movimiento falangista José Antonio Primo de Rivera) es manifestación de una clara voluntad de olvido.

27 Para Arendt, en referencia al mal radical, es un "elemento estructural en la esfera de los asuntos públicos que los hombres sean incapaces de perdonar lo que no pueden castigar e incapaces de castigar lo que ha resultado ser imperdonable" (Arendt, 1974: 260). Sobre el tema de los límites del perdón, resulta también inevitable remitir a Wiesenthal, 1996; así como a Jankélévitch 1967 y 1971 (entre estos dos últimos escritos hay diferencias muy notables, y en el segundo de ellos algunas ideas, como la culpabilización colectiva de todo el pueblo alemán por el nazismo, me resultan particularmente discutibles, aunque este no sea el lugar para entrar en el tema).

${ }^{28}$ Schimitt (1949). Este escrito no se debe identificar con el texto que con el título muy similar de "Amnistía es la fuerza de olvidar" el propio Schmitt envió al diario El País, que es una versión del anterior con notables variaciones ad hoc publicada el 21 de enero de 1977, es decir, entre la amnistía limitada del Real Decreto-ley 10/1976, de 30 de julio y la más general del Real Decreto de 14 de marzo de 1977 y, sobre todo, de la Ley 46/1977, de 15 de octubre. Aquí me refiero únicamente al texto original. 
del texto pero para negar que la amnistía sea precisamente "un mero perdón" 29 . No podría imaginarse mayor inversión de valores que semejante petición de olvido de los crímenes nazis, no ya solo eludiendo pedir todo perdón por ellos, sino incluso ofreciendo recíprocamente al que debe amnistiar el mismo sucedáneo de perdón por sus implícitos crímenes ${ }^{30}$. Si tiene sentido perdonar sin olvidar, la llamada a olvidar sin perdonar propone una inversión que autoriza toda la desconfianza.

Para sintetizar, en situaciones de llamada justicia transicional y restaurativa, aunque no la justicia, sí tal vez la realización de la paz y la construcción de una sociedad democrática pueden justificar alguna forma de perdón jurídico, siempre sometido a límites y condiciones. En la línea gradual antes comentada, la legitimidad de los casos de justicia transicional aumenta en cuanto esta se acerca más al modelo restaurativo, distanciándose del meramente transaccional. Por ello, para ser legítimas, las medidas de perdón deberían ser especialmente cuidadosas no solo en la extensión de los delitos condonados, sino también en mostrar preocupación por otros procedimientos y condiciones que deben acompañar a estos momentos políticos, como la previsión de comisiones de la verdad o similares y de medidas apropiadas de compensación y reconocimiento de las víctimas, entre las que deben figurar modos institucionales para evitar su olvido.

\section{Situaciones de necesidad}

Las situaciones de necesidad, como también las de acusada conveniencia, apelan a la idea de especial utilidad pública y podrían ser una razón justificativa del derecho de gracia. Frente a la exclusión preliminar de todo motivo de conveniencia como justificativo se pueden avanzar dos consideraciones. Ante todo, la distinción entre motivos de conveniencia y de necesidad es en sí misma espinosa porque la transición entre una y otra parece ser gradual y a veces movediza: un hacinamiento moderado de las cárceles puede suministrar una razón de conveniencia para excarcelar a internos no peligrosos con condenas cortas, pero un hacinamiento severo, que afecte a la seguridad y a los derechos más básicos de los propios internos, podría ser una razón de necesidad para ese mismo tipo de excarcelación; el intercambio de prisioneros en un conflicto bélico puede responder a conveniencia o a necesidad según circunstancias contingentes, como la moral de los combatientes o de la población, el momento de la guerra, etc.; la liberación de un condenado a cambio de su futura colaboración puede ser conveniente o necesaria según el tipo de organización criminal de que se trate; en fin, ¿es de conveniencia o es de necesidad ceder a la grave presión económica de otro Estado para que uno de sus ciudadanos sea eximido de una acusación penal o de una condena ${ }^{31}$ ? Sea como sea, un repaso

\footnotetext{
${ }^{29}$ Esta negación resulta especialmente irritante cuando se interpreta, como debe hacerse, en el contexto de la crítica de Schmitt a la "desnazificación": "Amnistía significa más que un mero perdón por una pequeña contravención. Debe ser más que un acto de compasión que a fin de cuentas no se puede negar a quien ha sido atormentado y perseguido durante años; amnistía es más que el cigarrillo que se ofrece a quien ha sido privado de todo derecho para demostrarse a sí mismo la propia humanidad" (cursivas mías).

${ }^{30}$ La postura de Carl Schmitt contrasta agudamente con la de arrepentimiento de Albert Speer, el ministro de Hitler que en el juicio de Núremberg reconoció su responsabilidad en "los tormentos de millones de seres humanos" causados por el nazismo. Speer, que fue el único ex nazi que participó en el Simposio celebrado a los 20 años de la primera edición americana del libro de Wiesenthal, afirmó allí, en un sensible texto: "Con el veredicto de culpabilidad [en el juicio de Núremberg] el tribunal castigó solo mi culpa jurídica. Más allá de ella subsiste la implicación moral. Incluso tras veinte años de prisión en Spandau, nunca podré perdonarme a mí mismo por el apoyo negligente y carente de escrúpulos a un régimen que llevó a cabo el asesinato sistemático de judíos y otros grupos de personas. Mi culpa moral no está sujeta a limitaciones y no podrá ser borrada en toda mi vida" (en Wiesenthal, 1996: 245).

${ }^{31}$ El caso no es de laboratorio: España, a través del ministro De Guindos, amenazó en el último momento con vetar el desembolso de un rescate de 8.500 millones de euros de la Unión Europea destinadas a
} 
como el anterior permite concluir que algunos motivos de conveniencia pueden ser tan importantes que resulten asimilables a los de necesidad.

Junto a lo anterior, supuesto que la conveniencia de la medida de gracia es elevada y, por tanto, próxima a la necesidad, lo más relevante para juzgar sobre la justificación de situaciones como las anteriores no es tanto la distinción entre necesidad y conveniencia como la existencia de proporcionalidad entre la importancia de la situación en cuestión y el alcance de la gracia: el indulto a un condenado para que sirva de confidente en un banda terrorista donde ya hay otros infiltrados puede ser más conveniente que necesario pero seguramente resulta más justificado que el indulto del jefe de una organización terrorista recién condenado a cambio de la liberación de un rehén secuestrado por su banda. Conforme a los argumentos anteriores, aquí hablo genéricamente de situaciones de necesidad incluyendo también las de particular o acusada conveniencia.

La aceptación de situaciones de necesidad como las ejemplificadas y otras similares como motivos justificados para la subsistencia del derecho de gracia es problemática por distintas razones, tanto sustantivas como procedimentales. Ello porque en su contenido mismo tales situaciones tienden a presentar un carácter dilemático o extremadamente conflictivo que por sí solo dificulta su justificación, que se puede complicar ulteriormente según los procedimientos que se establezcan para regularlas o codificarlas.

El carácter dilemático de muchas situaciones críticas se presenta no solo, como en los casos de clemencia o de justicia transicional, porque la gracia entre en conflicto con la justicia, sino también porque los propios criterios de justicia en juego pueden encontrarse en contraste entre sí. Los casos de secuestro con condiciones al Estado ilustran bien la grave tensión entre la evitación de un daño inmediato mediante el cumplimiento de la condición de los secuestradores y la previsible causación de más daños futuros como consecuencia del éxito del secuestro, tanto porque el mismo éxito puede incentivar nuevos secuestros como por el robustecimiento financiero o en efectivos personales del grupo delictivo ${ }^{32}$.

A ello se añade el problema procedimental. Si disolviéramos el dilema sustantivo proponiendo evitar el daño inmediato, disponer de una regla que garantice legalmente el cumplimiento del rescate sería una invitación irracional a secuestrar, por lo que lo racional sería no disponer de regla alguna (supuesta la legalidad de cualquiera de las dos soluciones) o, en todo caso, contar con una norma discrecional como, precisamente, las que suelen establecer el derecho de gracia. Si propusiéramos la solución opuesta, de asumir siempre y a ciegas el daño inmediato

\footnotetext{
Grecia si este país no concedía inmunidad a tres funcionarios europeos, uno de ellos español, allí procesados por un presunto delito de corrupción (cf. "España amenaza con vetar el rescate a Grecia por un conflicto judicial", El País, 17 de junio de 2017; y "Este español vale el rescate de Grecia", El Mundo, 18 de junio de 2017). Aunque el rescate se aprobó el mismo día, las noticias posteriores que he podido ver no recogen el resultado de la presión, que probablemente se decidió tratar discretamente.

32 Conflictos análogos se presentan en otros tipos de casos, como en la excarcelación de presos por masificación carcelaria o en la cesión ante amenazas de otro Estado. El caso de un secuestro con rehenes comentado por Zagrebelsky (1994: 94-96) - que se refiere al secuestro con rescate de dinero pero que también podría extenderse al atraco que termina en secuestro con petición de impunidad de los secuestradores- es diferente solo en el hecho de que es posible su codificación previendo expresamente una excepción similar a la del desistimiento de la tentativa, ya recogida en los códigos penales español o italiano, una solución que Zagrebelsky estima que no disminuiría necesariamente la función preventiva de la norma prohibitiva. Sin embargo, yo no tengo nada claro que semejante previsión no rebaje sustancialmente la función preventiva de la norma que prohíbe el secuestro (en esta línea, el art. 163.2 del Código penal español se limita a atenuar la pena ante el secuestro desistido dentro de los tres primeros días); así pues, en lo que respecta al dilema entre daños inmediatos o futuros, estos casos me parecen asimilables al comentado en el texto.
} 
evitando los futuros, la regla adecuada sería adoptar una estrategia Ulises de prohibición legal de negociar o pagar cualquier rescate, o, para lo que aquí interesa, excluyendo toda posibilidad de ejercer la gracia.

Obsérvese que en cualquiera de las opciones, el dilema se plantea porque estamos ante casos que, por excepcionales que puedan parecer, no son en realidad únicos, ya que no son irrepetibles en los rasgos relevantes que los caracterizan ${ }^{33}$. Este reconocimiento nos devuelve al reto que la discrecionalidad de la gracia presenta al principio de igualdad de trato, es decir, al problema de si el derecho de gracia (entendido como discrecional) está justificado racional y moralmente por razones de clemencia, que en otro lugar he analizado y resuelto negativamente (Ruiz Miguel, 2018a: §5). ¿Introduce alguna diferencia el argumento del interés general? Creo que, en paralelo a la justicia transicional, también situaciones de necesidad graves como las aquí contempladas pueden justificar una respuesta proporcionada mediante la institución de la gracia. La gracia es seguramente la única "válvula de seguridad" 34 capaz de operar anticipadamente en tales casos, y por razones similares a las que en los sistemas penales civilizados excusan ex post facto los delitos cometidos en estado de necesidad ante la opción entre dos bienes de igual valor. Así pues, la prohibición constitucional de toda posibilidad de gracia podría ser imprudente y poco razonable en ese tipo de casos.

\section{Los procedimientos: amnistías, indultos generales e indultos particulares}

Queda por comentar el diseño institucional más apropiado para abordar situaciones críticas como las anteriores, en las que desaparece la apelación al equilibrio entre el poder judicial y el legislativo que protagonizan las razones de equidad y de clemencia. Ahora el debate principal se traslada a la atribución del protagonismo al poder ejecutivo $o$ al legislativo y a la diferencia entre la figura del indulto y la de la amnistía.

En la tradición de la gracia la posesión de la prerrogativa por el rey hacía meramente académica la distinción entre amnistías e indultos. Así, en el surco del modelo británico, tal distinción es inexistente en la Constitución estadounidense, que atribuye al presidente la prerrogativa de "conceder conmutaciones e indultos (reprieves and pardons) por delitos contra los Estados Unidos, excepto en casos de impeachment" (art. II.2). En otros sistemas constitucionales hay variedad de denominaciones y regímenes, si bien parece ser regla general que la aprobación de amnistías e indultos generales se reserve al parlamento mientras los indultos particulares se atribuyan al poder ejecutivo (Aguado, 2001: § I.2). En la medida en que se admita la institución de la gracia, ese parece un criterio de distinción razonable y las razones que Alexander Hamilton dio en El Federalista defendiendo la regulación de la Constitución de los Estados Unidos son históricamente contingentes y en general poco persuasivas ${ }^{35}$.

\footnotetext{
${ }^{33}$ En su estudio sobre el tema de la gracia, Zagrebelsky (1974: 93-96) dedica unas páginas al problema del caso único para justificar el uso de la gracia precisamente por razones excepcionales de utilidad social en situaciones irrepetibles, una categoría que él mismo reconoce como precaria porque en teoría cualquier situación es repetible, por lo que termina por debilitarla conceptualmente mediante el criterio de la "presumible irrepetibilidad" o la mera "singularidad presumible y razonable del caso".

${ }^{34}$ La idea la formuló Jhering (1877: 306).

${ }^{35}$ Me refiero no tanto al párrafo del capítulo 74 en el que Hamilton apela a razones de "humanidad y buena política" para excepcionar la "necesaria severidad" de los códigos penales en referencia a los indultos que aquí se han considerado de clemencia y equidad, sino sobre todo al siguiente párrafo, donde defiende la facultad presidencial de perdonar ante delitos de traición en momentos críticos de insurrecciones o rebeliones, en especial como oferta o promesa a cambio del cese de aquellas. Es en ese marco tan restringido en el que Hamilton puede respaldar más fácilmente la prerrogativa presidencial
} 
En España, la distinción doctrinal entre indulto general y amnistía -inexistente por ejemplo en Alemania ${ }^{36}$ - está lejos de ser clara. Tradicionalmente, junto a la denominación medieval de "perdón", parece que en las leyes recogidas en la Novísima Recopilación y hasta mediado el siglo XIX se utilizó sobre todo el término de "indulto", diferenciándose entre indultos particulares y generales ${ }^{37}$. Cuando en 1856 se introduce constitucionalmente el término "amnistía" queda oscura la relación de esta con los indultos generales ${ }^{38}$. A partir de entonces la doctrina utiliza criterios imprecisos y variopintos: la amnistía borra el delito, el indulto todo o parte de la pena (Gutiérrez, 1866: 85-86); el indulto, como perdón, es menos que la amnistía, que es olvido, y mientras aquel es un acto de clemencia del gobierno en atención al interés del reo, esta se fundamenta en altas razones políticas de interés general y se aprueba por una ley especial (Groizard, 1872: 588); en fin, la amnistía afecta a delitos políticos y puede concederse en cualquier momento, mientras que el indulto solo es posible después de fallada la causa (Viada y Villaseca, 1874: 203). No es de extrañar que en su exhaustivo estudio sobre el indulto, de 1911, Dorado Montero escribiera que los indultos generales "son bastante parecidos, por su índole y sus efectos, a las amnistías" (Dorado Montero, 1911: 439-440).

La Constitución de la II República introdujo la novedad de la triple distinción entre amnistías, reservadas al parlamento, indultos generales, prohibidos, $y$, en fin, indultos individuales, otorgables por el tribunal supremo o, con ciertas condiciones, por el presidente de la República (art. 102). En contraste, nuestra Constitución de 1976 no menciona las amnistías y hace referencia solo al derecho de gracia "con arreglo a la ley" prohibiendo a la vez los indultos generales (art. 62.i). La doctrina contemporánea que acepta la posibilidad de que el parlamento apruebe leyes de amnistía interpreta la prohibición de los indultos generales como dirigida al rey (e indirectamente al ministro que refrenda el acto), recogiendo también algunas de los no siempre claros criterios de distinción ya avanzados por los autores del siglo XIX (Aguado, 2001: 100-101 y García Mahamut, 2004: 42-53 y 66-70).

A mi modo de ver, la distinción fundamental es la que diferencia entre, de un lado, amnistías e indultos generales y, de otro, indultos particulares. La distinción ulterior entre amnistías e indultos generales por el contenido eminentemente político de las amnistías, que es radicalmente imprecisa, puede aceptarse a efectos denominativos pero carece de especial relevancia práctica. Más importante es el significado sustantivo de la distinción entre amnistías (e indultos generales) e indultos

frente a quienes durante la redacción de la constitución habían pedido sin éxito el concurso del legislativo. Frente a ellos, restringiendo mucho el conjunto de casos posibles, esgrime como principal argumento la necesidad de anticiparse y obrar con rapidez para "restablecer la tranquilidad en el país". Por lo demás, sus argumentos sobre la mayor fiabilidad de "un solo hombre prudente y de buen sentido" sobre cualquier cuerpo colectivo resultan sesgados y endebles (cf. Hamilton, Madison y Jay, 1971: 379-380; trad. cast.: 317-318).

${ }^{36}$ Donde se distingue solo entre indulto (particular) y amnistía: cf. Jescheck y Weigend (2002: 994).

${ }^{37}$ Cf. Vizmanos y Álvarez Martínez, 1853: 264. La distinción entre "indultos particulares y generales" consta ya en el código penal de 1822, que somete la facultad de indultar a una detallada regulación con fuertes limitaciones (arts. 156-170). Tales limitaciones estaban previstas en la Constitución de Cádiz, de 1812, que reconoció la facultad del rey de "indultar a los delincuentes con arreglo a las leyes" (art. $171.13^{a}$ ), fórmula que atraviesa todas nuestras constituciones posteriores y que recoge la actual.

${ }^{38}$ En 1856 una reforma a la Constitución de 1845 estableció que el rey "necesitará estar autorizado por una ley especial... para conceder indultos generales y amnistías" (art. 9.1 ${ }^{\circ}$ del Acta adicional a la Constitución de 1845, R.D. 15 sept 1856; lo que moderó el art. 52.10 de la constitución no promulgada de 1856, que prohibía los indultos generales). La Constitución de 1869 repitió la exigencia (art. $74.5^{\circ}$ ) y el código penal de 1870 es el primero que distingue entre la "amnistía, la cual extingue por completo la pena y todos sus efectos", y el "indulto", sometido a condición resolutoria por violación de la prohibición de habitar en el lugar en que viva el ofendido (art. $132.3^{\circ}$ y $4^{\circ}$ ), una distinción que ha perdurado prácticamente inalterada en todos los códigos penales posteriores con excepción del vigente, de 1995, que ya no menciona la amnistía. Entre tanto, la Constitución de 1876 volvió a la fórmula de Cádiz, eliminando toda referencia a indultos generales o amnistías (art. $54.3^{\circ}$ ). 
particulares, que depende — como se concluyó en el apartado § $2.3-$ de si el sentido de la medida de gracia es seleccionar a sus beneficiarios de manera genérica e indeterminable o, por el contrario, con acepción de personas. Una vez determinada sustantivamente la naturaleza general o particular de la medida, el procedimiento institucional pertinente va de suyo: mientras las amnistías y los indultos generales deben ser aprobadas por el parlamento ${ }^{39}$, los indultos particulares deberían corresponder al poder ejecutivo ${ }^{40}$. Idealmente, justo en aras del interés general, parece razonable dejar abierta la constitucionalidad de las leyes de amnistía, típicas tanto de los procesos de justicia transicional como de algunas, solo algunas, de las situaciones de necesidad antes comentadas.

En estas últimas situaciones, en efecto, la utilización del indulto general (o la amnistía) o del indulto particular variará según los casos, a veces incluso dentro de situaciones aparentemente del mismo tipo: si el hacinamiento carcelario parece exigir un indulto general, debiéndose tener en cuenta categorías de delitos y penas, y la liberación de un preso como rescate de un secuestro es necesariamente un indulto particular, un intercambio de prisioneros puede ser particular o general según los casos. De todas formas, una variable a tener en cuenta para recurrir al indulto particular es la especial urgencia que puede caracterizar a las situaciones de necesidad.

Por lo demás, como se ha visto antes en el § 3.1., otra diferencia que merece destacarse aquí entre las amnistías por razones de justicia transicional y las medidas de gracia derivadas de situaciones de necesidad es que, en los últimos años, las primeras están convirtiéndose en objeto de limitaciones por parte del Derecho internacional aplicables a través de tribunales internacionales, que comienzan a reconocer ciertos derechos de la víctimas ante graves violaciones de derechos básicos estatalmente consentidas o convalidadas.

\section{Conclusión}

Por comenzar sintetizando lo sustancial del diseño institucional que se desprende de este estudio, el ideal sería que la prerrogativa de gracia se redujera constitucionalmente a motivos de utilidad pública, confiriendo al parlamento la facultad de aprobar amnistías e indultos generales mediante leyes específicas y al gobierno la de los indultos particulares. En un segundo paso, la regulación legal de la prerrogativa debería limitar los indultos particulares a aquellas situaciones excepcionales de necesidad cuya urgencia o circunstancias específicas hagan imposible, inaceptable o inconveniente la generalización de la medida. El indulto particular debería alcanzar también a un supuesto que en algunos sistemas jurídicos, entre ellos el español, no es hoy legalmente resoluble: la liberación de personas procesadas pero no condenadas. Last but not least, dicha regulación debería romper con la poco virtuosa

\footnotetext{
${ }^{39}$ Dejo aquí a un lado el complejo debate sobre la mayor legitimidad del sometimiento de las amnistías a referéndum, que ha sido defendido como forma óptima de deliberación democrática (cf. Teitel 2000: 58-59 y, sobre todo, Gargarella 2015, especialmente en relación con el caso argentino), pero que también puede someterse a objeciones liberales obvias (así, Escudero, 2017: 112-113, con especial referencia a la defensa de la labor de la Corte Constitucional colombiana por parte de Ferrajoli 2016).

40 El criterio material de que el indulto afecta solo a la pena como efecto mientras que la amnistía implicaría un cierto olvido del delito mismo (que puede llegar a ser máximo cuando se trata de delitos que no deberían haberlo sido, como los delitos políticos en situaciones dictatoriales), flaquea ante amnistías que perdonan delitos comunes o en todo caso delitos gravísimos que no dejan de serlo por su motivación política: así, cuando Valcárcel (2010: 130-131) formula límpidamente que "el indulto supone el perdón del yerro y la amnistía, que la situación era errada", enseguida debe admitir la complicación de las amnistías de conductas infames en condonación de periodos autocráticos.
} 
tradición de la plena discrecionalidad de la gracia sometiendo la competencia de indultar del gobierno a alguna forma de control judicial previo ${ }^{41}$.

En el recorrido aquí realizado se ha intentado fundamentar la anterior conclusión revisando las principales justificaciones de la gracia y la indulgencia. En un primer apartado se ha analizado la presunta justificación histórica de la prerrogativa de gracia, basada en la idea de soberanía, y su contraste con la idea de justicia, así como con las exigencias del Estado de Derecho. Desechada esa tradicional concepción puramente discrecional de la gracia, se ha estudiado luego si tanto la justicia como la gracia pueden justificar todavía la indulgencia al amparo de tres rúbricas diferentes: la equidad, la clemencia y la utilidad pública.

En la equidad la gracia se da la mano con la justicia o, más precisamente, con una forma de justicia indulgente que modera la justicia rigurosa. Pero la equidad debe situarse en el ámbito judicial, controlado y moderado por la atención del legislador, y no en el del poder ejecutivo y en la figura del indulto. En la clemencia, entendida restrictivamente como compasión o misericordia, la gracia se presenta en contraste con la justicia. Pero tampoco la indulgencia por razones de clemencia debe ser atribuida al poder de indultar del ejecutivo, sino esencialmente a la regulación legal mediante supuestos genéricos que, como los de enfermedades graves, trastornos mentales sobrevenidos o pena natural, puedan ser debidamente aplicados y controlados por los jueces y la administración penitenciaria. En fin, por la utilidad pública, que apela al interés general, la gracia puede justificarse como una excepción a la justicia en situaciones críticas, sea de naturaleza fundacional (justicia transicional o restaurativa), sea por otros motivos de especial necesidad.

En una palabra, el derecho de gracia, nacido como ilimitado, necesita límites, y en su manifestación mediante el indulto, límites severos.

\section{Bibliografía}

AGUADO RENEDO, C. (2001), Problemas constitucionales del ejercicio de la potestad de gracia, prólogo de Manuel Aragón, Madrid, Civitas.

ALMQVIST, J. (2013), "El respeto debido a las personas en tiempos de conflicto: el rol del régimen internacional de derechos humanos", en TURÉGANO, 2013, pp. 117-136.

ARENDT, H. (1974), The Human Condition, Chicago, The University of Chicago Press, que se cita por la trad. cast. de R. Gil Novales, La condición humana, Barcelona, Paidós, 1993.

\footnotetext{
${ }^{41}$ Sigo así, en lo sustancial, la propuesta de Liborio Hierro, que defiende un control judicial previo similar al previsto por la Ley Orgánica 2/2002, de 6 de mayo, sobre el Centro Nacional de Inteligencia; mi pequeña discrepancia, casi meramente nominal, está en que él sugiere que la potestad gubernativa no sería propiamente un indulto porque "la excarcelación [...] no tendría la insólita forma de un perdón ni la indeseable consecuencia de la irrevocabilidad" (Hierro, 2017, §9). Digo "casi nominal" por varias razones: (a) mi propuesta no se limita a excarcelaciones, sino que incluye condonaciones de pena y exculpaciones previas al juicio que no pueden considerarse perdón en ningún sentido (por ejemplo, para casos como el comentado supra, nota 3632), pero que tampoco veo inconveniente en que se sigan denominando "indulto"; (b) la irrevocabilidad no es un rasgo necesario de los indultos, como lo prueba que la vigente ley española admita su concesión condicional y revocable (véase supra, nota 21); y (c) me parece más prudente, ante posibles tachas de inconstitucionalidad, que la regulación legal del derecho de gracia reconozca excepcionalmente algún supuesto de indulto particular en lugar de la supresión total de esa figura.
} 
ARISTÓTELES (1985), Ética a Nicómaco, ed. bilingüe de María Araujo y Julián Marías, Madrid, CEC, $4^{\mathrm{a}}$ ed.

BETEGÓN, J. (2013), "El castigo retributivo en los procesos de justicia transicional: análisis de un debate", en TURÉGANO, 2013a, pp. 25-46.

DE PÁRAMO ARGÜELLES, J.R. (2013), "Argumentaciones y negociaciones en los procesos de transición política”, en TURÉGANO, 2013a, pp. 3-24.

DERRIDA, J. (1999), Le Siècle et le Pardon, en Le Monde des Debats; también, por donde se cita, en Foi et savoir; suivi de Le Siècle et le Pardon (entretien avec Michel Wieviorka), París, Ed. du Seuil, 2000 (edición digital en http://redaprenderycambiar.com.ar/derrida/textos/siglo perdon.htm).

DORADO MONTERO, P. (1911), "Amnistía e indulto", en El derecho protector de los criminales, Madrid, Librería General de Victoriano Suárez, 1915, pp. 399-467.

DUFF, R. A. (2011), "Mercy", en J. Deigh y D. Dolinko (eds.), Philosophy of Criminal Law, Oxford, Oxford University Press, pp. 467-492.

ELSTER, J. (2004), Closing the Books. Transitional Justice in Historical Perspective, Cambridge, Cambridge University Press.

ESCUDERO, R. (2017), "Debatiendo sobre justicia transicional: memoria, perdón y castigo", en J. CERDIO, P. de LARRAÑAGA, y P. SALAZAR (eds.), Entre la libertad y la igualdad. Ensayos críticos sobre la obra de Rodolfo Vázquez, México, UNAM-Instituto de Investigaciones Jurídicas, 2018, tomo I, pp. 99-115 (el libro completo en https://biblio.juridicas.unam.mx/bjv/detalle-libro/4588-entre-lalibertad-y-la-igualdad-ensayos-criticos-sobre-la-obra-de-rodolfo-vazquez-tomoi).

FERRAJOLI, L. (2016), "La justicia penal transicional para la Colombia del posconflicto y las garantías para la paz interna", Revista Crítica Penal y Poder, 10 , pp. $146-161$

(en http://revistes.ub.edu/index.php/CriticaPenalPoder/article/view/15489).

FORCADA BARONA, I. (2011), Derecho Internacional y Justicia Transicional. Cuando el Derecho se convierte en religión, Cizur Menor, Aranzadi.

GARCÍA MAHAMUT, R. (2004), El indulto. Un análisis jurídico-constitucional, Madrid, Marcial Pons.

GARGARELLA, R. (2015), "La democracia frente a los crímenes masivos: una reflexión a la luz del caso Gelman", Revista Latinoamericana de Derecho Internacional, n. 2., pp. 1-15 (http://www.revistaladi.com.ar/numero2-gargarella/).

GIL Y GIL, A. y MACULAN, E. (2013), "Responsabilidad de proteger, Derecho penal internacional y prevención y resolución de conflictos", en TURÉGANO, 2013, pp. 137-165.

GROIZARD, A. (1872), El código penal de 1870 concordado y comentado, Burgos.

GUTIÉRREZ, B. (1866), Examen histórico del Derecho penal, Madrid.

HAMILTON, A., MADISON, J. y JAY, J. (1971), The Federalist or, The New Constitution 
[1788], Londres, Dent; trad. cast. de G. R. Velasco, El Federalista, México, FCE, $2^{\mathrm{a}}$ ed., 2001.

HAMPTON, J. (1988a), "The Retributive Idea», en J.G. MURPHY y J. HAMPTON, 1988, pp. 111-161.

- (1988b), "Forgiveness, resentment and hatred", en J.G. MURPHY y J. HAMPTON, 1988, pp. 35-87.

HIERRO SÁNCHEZ-PESCADOR, L. L. (2017), "Sobre el indulto. Razones y sinrazones" (manuscrito).

HUME, D. (1777), Essays. Moral, Political, and Literary, ed. de Eugene F. Miller sobre la ed. de 1889, Indianapolis, Liberty Fund, 1987.

HUNTINGTON, S.P. (1991), The Third Wave. Democratization in the Late Twentieth Century, Norman y Londres, University of Oklahoma Press.

JANKÉLÉVITCH, V. (1967), Le pardon, París, Aubier-Montainge.

— (1971) "Pardonner?", en "Pardonner?", en L'imprescriptible. Pardonner? Dans l'honneur et la dignité, Paris, Éditions du Seuil, 1986, pp. 9-63.

JESCHECK, H.H. y WEIGEND, Th. (2002), Tratado de Derecho penal. Parte General, $5^{\mathrm{a}}$ ed., trad. cast. de Miguel Olmedo Cardenete, Granada, Comares.

JHERING, R. von (1877), Der Zweck im Recht, que se cita por la trad. cast. de D. Abad de Santillán, El fin en el Derecho, Puebla-México, Editorial Cajica, 1961.

- (1885), Scherz und Ernst in der Jurisprudenz. Eine weih-nachtsgabe für das juristische publikum, que se cita por la trad. cast. de T. A. Banzhaf y M. S. Luque, Bromas y veras en la ciencia jurídica. Un presente navideño para los lectores de obras jurídicas, Madrid, Cívitas, 1987.

KANT, I. (1795), Zum ewigen Frieden. Ein philosophischer Entwurf, que se cita por la trad. cast. de F. Rivera Pastor, La paz perpetua, Madrid, Espasa-Calpe, $5^{\mathrm{a}}$ ed., 1972.

KLINKNER, M. y SMITH, E. (2015), "The Right to Truth, Appropiate Forum and The International Criminal Court", en SZABLEWSKA y BACHMANN, 2015, cap. 1.

KOGAN, V. (2015), "Implementing the Judgments of the European Court of Human Rights from the North Caucasus: A Closing Window for Accountability or a Continuing Process of Transitional Justice?", en SZABLEWSKA y BACHMANN, 2015, cap. 7 .

MOLINA, F. y CARRACEDO, E. (eds.) (2018), El indulto, pasado, presente y futuro, Montevideo-Buenos Aires, Editorial B de f.

MURPHY, J. (1988), “Forgiveness and resentment”, en MURPHY y HAMPTON, 1988, pp. 14-34.

MURPHY, J.G. y HAMPTON, J. (1988), Forgiveness and Mercy, Cambridge, Cambridge University Press.

NINO, C.S. (1996), Radical Evil on Trial, New Haven, Yale University Press, que se cita por la ed. cast. de G. Maurino y trad. de M. Böhmer, Juicio al mal absoluto. ¿Hasta dónde debe llegar la justicia retroactiva en casos de violaciones masivas 
de los derechos humanos?, $3^{\mathrm{a}}$ ed., Buenos Aires, Siglo Veintiuno Editores Argentina, 2015.

NOUWEN, S.M.H. (2012), "Justifying justice", en J. CRAWFORD y M. KOSKENNIEMI, The Cambridge Companion to International Law, Cambridge University Press, 2012, pp. 327-351.

OLLÉ SESÉ, M. (2013), "Derecho penal, amnistías, indultos y cosa juzgada fraudulenta en los procesos transicionales", en TURÉGANO, 2013a, pp. 79-115.

RANGELOW, I. y TEITEL, R. (2014), "Transitional Justice", en M. KALDOR y I. RANGLEOW (eds.), The Handbook of Global Security Policy, Hoboken, John Wiley \& Sons.

RIEFF, D. (2016), In Praise of Forgetting: Historical Memory and Its Ironies, Yale University Press, que se cita por la trad. cast. De Al Major, Elogio del olvido. Las paradojas de la memoria histórica, Debate, 2017.

RUIZ MIGUEL, A. (2017), "Gracia y justicia: el lugar de la equidad", Derecho PUCP. Revista de la Facultad de Derecho (Lima), n. 79, 2017, pp. 77-98 (también en http://revistas.pucp.edu.pe/index.php/derechopucp).

- (2018a), "Gracia y justicia: el lugar de la clemencia (en torno a la pena natural)", InDret. Revista para el Análisis del Derecho (http://www.indret.com/es/), 2/2018, pp. 1-25.

- (2018b), "Gracia y justicia: soberanía y excepcionalidad", Revista Española de Derecho Constitucional, n. 113, mayo-agosto, pp. 13-35.

SÁNCHEZ-VERA, J. (2008), "Una lectura crítica de la ley de indulto”, InDret, abril, pp. 1-32.

SCHMITT, C. (1949), "Amnestie oder die Kraft des Vergessens", Crist und Welt, ahora en http://clubtiberino.blogspot.com.es/2007/07/lettere-la-stampa-sulcosiddetto.htm|\#kraft, que incluye una traducción italiana de A. Caracciolo (consulta 27 agosto 2017).

— (1977), "Amnistía es la fuerza de olvidar", El País, 21 de enero.

SEIXAS, J. (2014), "Diferenças entre indulto, graça e anistia", en https://julianaseixas83.jusbrasil.com.br/artigos/172140916/diferencas-entreindulto-graca-e-anistia (consulta 14 sept. 2017).

SZABLEWSKA, N. y BACHMANN, S.-D. (2015), "Current Issues and Future Challenges in Transitional Justice", en N. SZABLEWSKA y S.-D. BACHMANN (eds.), Current Issues in Transitional Justice. Towards a More Holistic Approach, Cham, Springer 2015, pp. 339-361.

TEITEL, R.G. (2000), Transitional Justice, Oxford, Oxford University Press.

TURÉGANO MANSILLA, I. (ed.) (2013a), La justicia de transición: concepto, instrumentos y experiencias, Bogotá, Editorial Universidad del Rosario.

- (2013b), "Los principios de una justicia transicional multinivel", en TURÉGANO, 2013a, pp. 47-76.

TURNER, C. (2013), “Deconstructing Transitional Justice”, Law Critique, n. 24, pp. 193-209. 
VALCÁRCEL, A. (2010), La memoria y el perdón, Barcelona, Herder.

VÁZQUEZ, R. (2009), "Memoria, perdón y castigo", en Las fronteras morales del derecho, México, Fontamara, cap. 3.

VIADA Y VILLASECA, S. (1874), Código penal reformado de 1870, Barcelona.

VIZMANOS, T.M. de y ÁLVAREZ MARTÍNEZ, C. (1853), Comentarios al Código penal, Tomo I, $2^{\text {a }}$ ed., Madrid.

WIESENTHAL, S. (1996), The Sunflower. On the Possibilities and Limits of Forgiveness, with a symposium edited by Harry James James Cargas y Bonnie V. Fetterman, $2^{\mathrm{a}}$ ed. revisada y ampliada, Nueva York, Schocken Books, 1996 (trad. cast. de C. Ossés, Los límites del perdón. Dilemas racionales y éticos de una decisión, Barcelona etc., Paidós, 1998).

WILLIAMS, S.H. (2012), "A Feminist View of Mercy, Judgment, and the «Exception» in the Context of Transitional Justice", en A. SARAT (ed.), Merciful Judgements and Contemporary Society. Legal Problems, Legal Possibilities, Cambridge, Cambridge University Press, pp. 247-290.

ZAGREBELSKY, G. (1974), Amnistia, indulto e grazia. Profili costituzionali, Milán, Giuffré. 